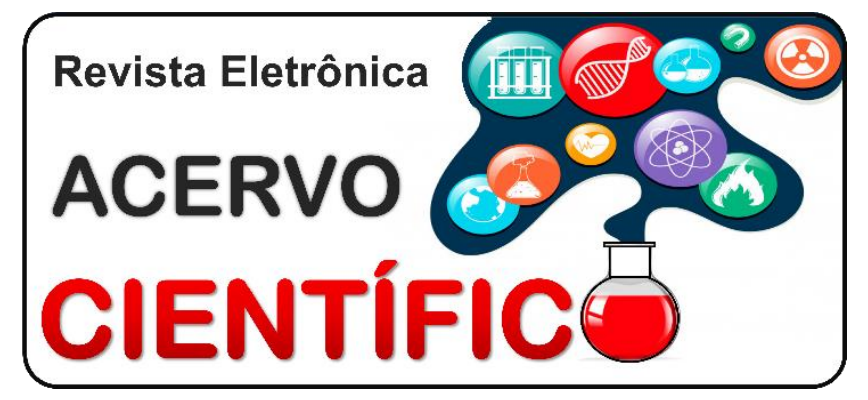

\section{ARTIGO ORIGINAL}

Recebido em: 2/2020

Aceito em: 2/2020

Publicado em: 5/2020

\title{
Perfil epidemiológico de mulheres com vaginose em exame papanicolaou de uma unidade de saúde de Belém - PA
}

\author{
Epidemiological profile of women with vaginosis in paper examination from a health unit in \\ Belém - PA
Perfil epidemiológico de mujeres com vaginosis en examen de papel em una unidad de salud em Belém - PA

Rafaela Antônio de Bastos Ribeiro ${ }^{1 *}$, Renan Perotes Albuquerque ${ }^{1}$, Max Rafael Almeida Rodrigues $^{1}$, Sheila Mara Dias ${ }^{1}$.

\begin{abstract}
Resumo: Este estudo teve como objetivo descrever o perfil epidemiológico das pacientes com diagnóstico de vaginose bacteriana, atendidas em uma Unidade Saúde da Família Belém - PA. Segundo variáveis de interesse social, demográfico e clínico. A pesquisa foi feita com mulheres acima de 18 anos as quais se submeteram ao exame citopatológico para rastreamento do câncer de colo uterino que consentiram em participar do estudo. Das 64 pacientes, 37\% tinham entre 21 a 30 anos de idade e metade são solteiras. Já o número de pacientes que tinham ensino médio completo dominou a pesquisa com $31 \%$. O uso do DIU esteve presente em $6 \%$ das pacientes. Quanto ao número de parceiros sexuais nos últimos três anos, foi observada uma maior taxa em relação às mulheres que tiveram entre um ou nenhum parceiro. Já o uso do preservativo ficou em $34 \%$. Em relação à DST, $97 \%$ referiram não ter tido nenhuma, enquanto $3 \%$ referiram. O perfil epidemiológico das pacientes com diagnóstico de vaginose bacteriana atendida na USF mostrou que mulheres jovens de baixa renda e com nível de escolaridade até o ensino médio apresentaram maior frequência de vaginose bacteriana.
\end{abstract}

Palavras-chave: Teste de Papanicolau, Epidemiologia, Centros de saúde.

\begin{abstract}
This study aimed to describe the epidemiological profile of patients diagnosed with bacterial vaginosis, seen at a Family Health Unit in Belém - PA. According to social, demographic and clinical variables. The survey was carried out with women over 18 years of age who underwent cytopathological examination for cervical cancer screening who consented to participate in the study. Of the 64 patients, 37\% were between 21 and 30 years of age and half are single. The number of patients who had completed high school dominated the survey with $31 \%$. IUD use was present in $6 \%$ of patients. As for the number of sexual partners in the past three years, a higher rate was observed in relation to women who had between one or no partner. The use of condoms was 34\%. Regarding STDs, $97 \%$ said they had none, while $3 \%$ reported it. The epidemiological profile of patients diagnosed with bacterial vaginosis treated at the FHU showed that young women with low income and with education level up to high school had a higher frequency of bacterial vaginosis.
\end{abstract}

Keywords: Papanicolaou test, Epidemiology, Health centers.

${ }^{1}$ Centro Universitário Metropolitano da Amazônia (UNIFAMAZ), Belém - Pará.

*E-mail: rafaelabastos_16@hotmail.com 
Resumen: Este estudio tuvo como objetivo describir el perfil epidemiológico de pacientes diagnosticados con vaginosis bacteriana, visto en una Unidad de Salud Familiar en Belém - PA. Según variables sociales, demográficas y clínicas. La encuesta se realizó con mujeres mayores de 18 años que se sometieron a un examen citopatológico para detectar el cáncer de cuello uterino y que aceptaron participar en el estudio. De los 64 pacientes, el $37 \%$ tenían entre 21 y 30 años y la mitad son solteros. El número de pacientes que habían completado la escuela secundaria dominó la encuesta con un $31 \%$. El uso del DIU estuvo presente en el $6 \%$ de los pacientes. En cuanto al número de parejas sexuales en los últimos tres años, se observó una tasa más alta en relación con las mujeres que tenían entre una o ninguna pareja. El uso de condones fue del $34 \%$. Con respecto a las ETS, el $97 \%$ dijo que no tenía ninguna, mientras que el $3 \%$ lo informó. El perfil epidemiológico de los pacientes diagnosticados con vaginosis bacteriana tratados en la FHU mostró que las mujeres jóvenes con bajos ingresos y con un nivel educativo hasta la escuela secundaria tenían una mayor frecuencia de vaginosis bacteriana.

Palabras clave: Prueba de Papanicolau, Epidemiología, Centros de salud.

\section{INTRODUÇÃO}

A vaginose bacteriana (VB) é uma das principais infecções vaginais em mulheres em idade fértil e pode ser causada por diversos fatores tais como a falta de higiene ou desequilíbrio hormonal sendo desconsiderada como Doença Sexualmente Transmissível (DST) (LIMA AP, 2015). Tendo em vista a alta frequência dos corrimentos vaginais e sua variedade de etiologias, torna-se imprescindível o seu correto diagnóstico (JALIL E, 2006).

É necessário atentar-se para as características clínicas do corrimento, a VB é uma manifestação clínica caracterizada pelo aumento da quantidade de corrimento vaginal fétido. Os critérios de Amsel permite diagnóstico de VB quando 3 dos 4 critérios são detectados: 1 - $\mathrm{pH}$ vaginal $>4,5$; 2 - teste positivo de aminas com KOH (Hidróxido de Potássio) 10\%; 3- presença de células alvo; 4) presença de corrimento vaginal branco, fino e homogêneo (SOUSA G, 2012). O exame de citologia oncótica (PCCU), Papanicolau, ou cervicovaginal é de extrema importância para prevenção do câncer de colo uterino e também para avaliação da microbiota vaginal, auxiliando também no diagnostico de VB (OLIVEIRA AB, et al., 2007; NAI GA, et al., 2007).

O PCCU pode ser feito em unidades de saúde da rede pública ou em clínicas privadas. É de fundamental importância que os profissionais de saúde orientem sobre qual o objetivo do exame e como é realizado, devendo ser informado também sobre seus pré-requisitos para a realização (não ter relações sexuais nos dois dias anteriores ao exame, evitar uso de duchas, medicações vaginais, anticoncepcionais locais em 48 horas antes do exame e não estar menstruada). O procedimento é realizado por meio da inspeção do canal vaginal e do colo uterino, posteriormente é coletado células da ectocérvice e endocérvice para análise em laboratório. O exame deve ser realizado anualmente após dois exames seguidos (intervalo de um ano) apresentarem-se normais. (TORTOLA GJ et al., 2005).

A susceptibilidade do sistema genital feminino a ter inflamações e vaginoses também se deve a atividade sexual, número de parceiros sexuais, fase do ciclo menstrual, imunidade, fator socioeconômico, idade (terceira a quinta década de vida), uso de duchas vaginais, de calças justas, de dispositivo intra-uterino (DIU), de contraceptivos orais e a eliminação da microbiota normal por antibióticos, também devido à localização anatômica do trato genital feminino, e a gravidez. O tabagismo é fator de risco controverso, significativo somente em alguns estudos (JALIL EM et al., 2006; FERREIRA ECMF et al., 2013).

Em mulheres com idade reprodutiva, a barreira contra lesões é o epitélio escamoso altamente proliferativo. Já quando mais jovem, em crianças e, em mulheres em pós-menopausa, essa barreira atrofia gerando oportunidade de infecção e desenvolvimento de lesões inflamatórias (JALIL EM et al., 2006; BRASIL, 2011).

Dentre essas infecções, uma das mais frequentes é a causada pelo agente etiológico Gardnerella vaginallis $(45 \%)$, haja vista gerar alterações celulares, podendo gerar alteração da microbiota vaginal 
presente, corioamnionite, endometrite pós-parto, complicações pós-parto para o recém nascido, risco de aborto, infecção urinária, recorrência de leucorréia, fator de risco para aquisição do vírus Herpes Simples tipo 2 e vírus da imunodeficiência humana (HIV). Esta infecção pode ser diagnosticada com teste de $\mathrm{KOH}$ positivo, contudo o Exame de PCCU acaba sendo o exame mais rápido, de custo mais baixo e fácil para diagnóstico (SOARES G et al., 2016).

Diante disso, o objetivo do presente estudo é identificar o perfil epidemiológico das mulheres que se submeteram ao exame citopatológico (PCCU) em uma USF de Belém - PA no período de Janeiro de 2014 a Abril de 2016 com resultados sugestivos de vaginose bacteriana.

\section{MÉTODOS}

Todos os pacientes entrevistados desta pesquisa foram estudados segundo os preceitos da Declaração de Helsinque e do Código de Nuremberg, respeitadas as Normas de Pesquisas envolvendo Seres Humanos (Res. CNS 196/96) do Conselho Nacional de Saúde após aprovação do projeto pelo Comitê de Ética em Pesquisa do Centro Universitário Metropolitano da Amazônia, autorizado pelo responsável pela secretaria de saúde do município e pelas pessoas incluídas no trabalho por meio do Termo de Consentimento Livre e Esclarecido, as quais receberam todas as informações necessárias antes de assiná-lo. A pesquisa foi realizada com mulheres acima de 18 anos em uma Unidade de Saúde da Família de Belém - PA as quais se submeteram ao exame citopatológico (Prevenção de Câncer de Colo de Útero - PCCU) para o rastreamento do câncer de colo uterino, no período de Janeiro de 2014 a Abril de 2016. Foram incluídos PCCU com resultados sugestivos de vaginose bacteriana no período de Janeiro de 2014 até Abril de 2016 realizados em uma USF de Belém-PA. Foram excluídos PCCU as que não apresentaram dados registrados e as que não apresentaram dados sugestivos de vaginose bacteriana. O projeto foi aprovado no Comitê de Ética em Pesquisa (CEP) sob parecer número 2.017.215.

Os dados coletados constam no livro de registros da USF escolhida pela pesquisa, onde foram analisadas as mulheres que realizaram Papanicolau na Unidade escolhida e tiveram resultados sugestivos de vaginose bacteriana, cujas variáveis analisadas como fatores de risco são: idade, estado civil, nível de escolaridade, renda, número de filhos, uso de DIU, número de parceiros, uso de preservativo e histórico de DST.

A pesquisa é de caráter observacional de corte transversal, de caráter descritivo e analítico. Para a coleta de dados, o trabalho foi conduzido por meio de um protocolo próprio e previamente estruturado construído pelos próprios autores, que nele contém características sócio demográficas, características sobre o tratamento medicamentos e sobre hábitos de vida. O protocolo foi apresentado ao paciente em local reservado de escolha do pesquisado, eles receberam o questionário e qualquer dúvida foi esclarecida pelos autores do trabalho. As informações obtidas por meio dos instrumentos de coleta de dados foram digitadas em planilha com tabelas e gráficos obtidas no Microsoft Excel e Word.

\section{RESULTADOS}

Por meio da coleta de dados foi identificado uma quantidade de 64 mulheres sendo $18,75 \%(n=22)$ de 18-20 anos, 34,37\% $(n=22)$ entre 21-30 anos, 15,62\% $(n=10)$ entre 31-40, 18,75 $(n=12)$ entre 41-50 anos, 6,25\% ( $n=4)$ entre 51-60 anos, 6,24\% $(n=4)$ entre 61-80 anos de idade. Quanto á análise de estado civil, $50 \%(n=32)$ consta como "solteira", $40,63 \%(n=26)$ são casadas e o restante $(n=6)$ consta como "outras formas de relacionamento não especificadas". Foi encontrado que a maioria possui ensino fundamental completo e ensino médico completo ( $n=23$ e $n=29$ especificamente).

Quanto à renda familiar, 41 mulheres (64\%) indica que ganha até 1 salário mínimo, destacando-se que 7 mulheres não possuem renda. Do total, 35 mulheres (54\%) possui 1 ou 2 filhos. De acordo com a pesquisa, analisando o grupo familiar, foi encontrado que do universo de 64 mulheres, 56 fazem parte de uma família com 2 a 5 pessoas no total, destacando-se que o restante $(n=8)$ faz parte de famílias com 6 a 9 pessoas (Gráfico 1). 
Gráfico 1 - Análise de grupo familiar de mulheres com exames sugestivos de vaginose.

\section{GRUPO FAMILIAR}

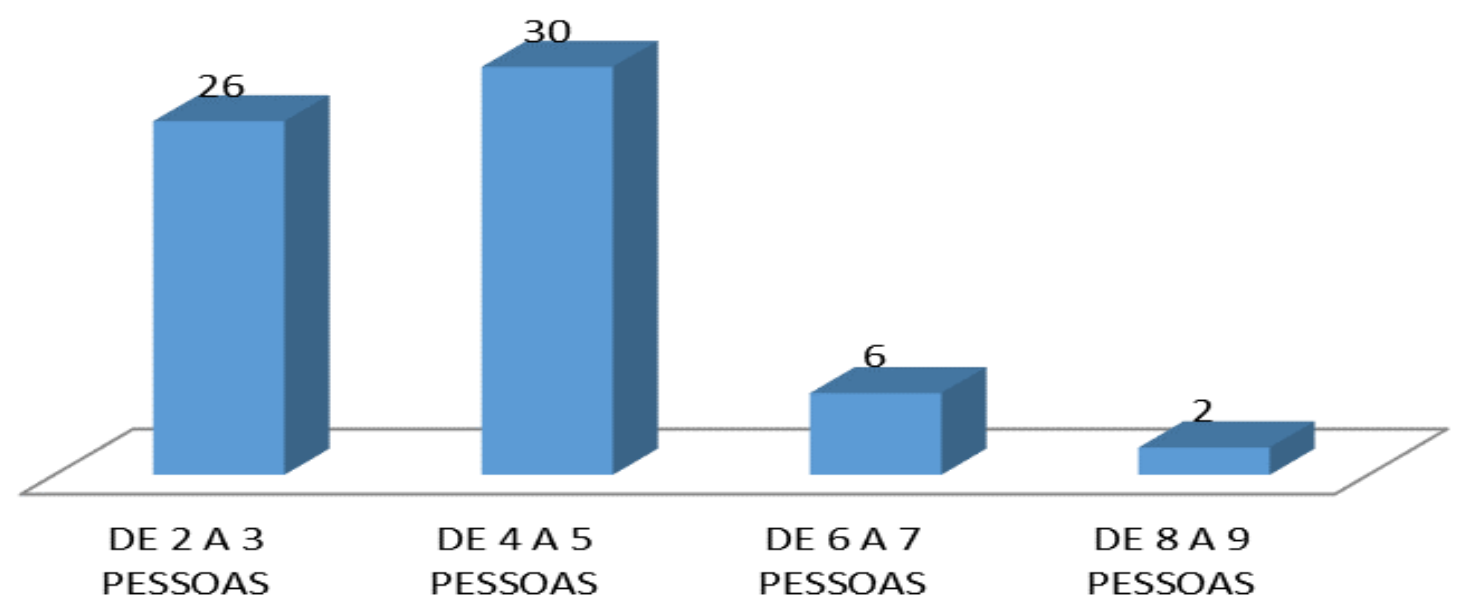

Fonte: Ribeiro RAB, et al., 2020.

A partir da análise de dados, foi encontrado nesta pesquisa que $94 \%(n=60)$ das mulheres, pacientes com exames sugestivos de vaginose bacteriana da ESF escolhida, não utilizam o DIU (Dispositivo Intra Uterino) como forma de método anticoncepcional e o restante $(6 \%-n=4)$ utilizada o dispositivo como método anticoncepcional (Gráfico 2).

Gráfico 2 - Uso do DIU por mulheres com exames sugestivos de vaginose bacteriana.

\section{USO DE DIU}

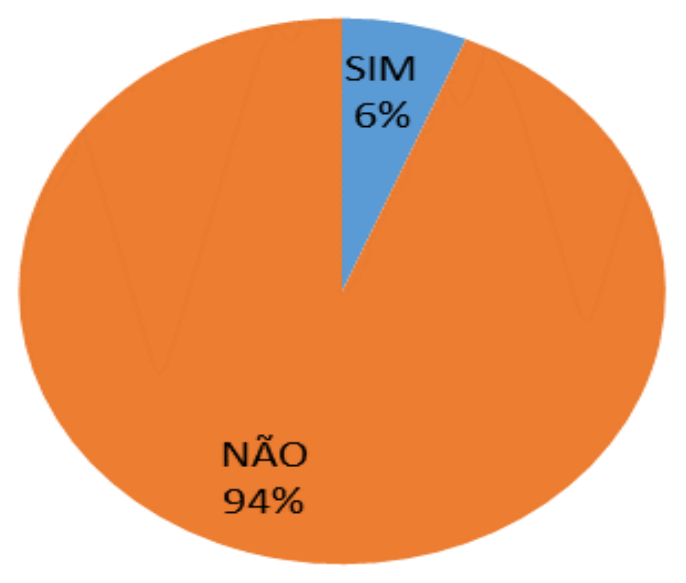

Fonte: Ribeiro RAB, et al., 2020.

Já analisando o uso do preservativo na relação sexual de mulheres com exames sugestivos de vaginose bacteriana da ESF escolhida para a pesquisa, 66\% $(n=42)$ relataram não utilizar durante a relação, enquanto o restante $(34 \%-n=21)$ relata que utiliza durante o ato sexual (Gráfico 3). 
Gráfico 3 - Uso do preservativo em relações sexuais de mulheres com exames sugestivos de vaginose bacteriana.

\section{USO DE PRESERVATIVO}

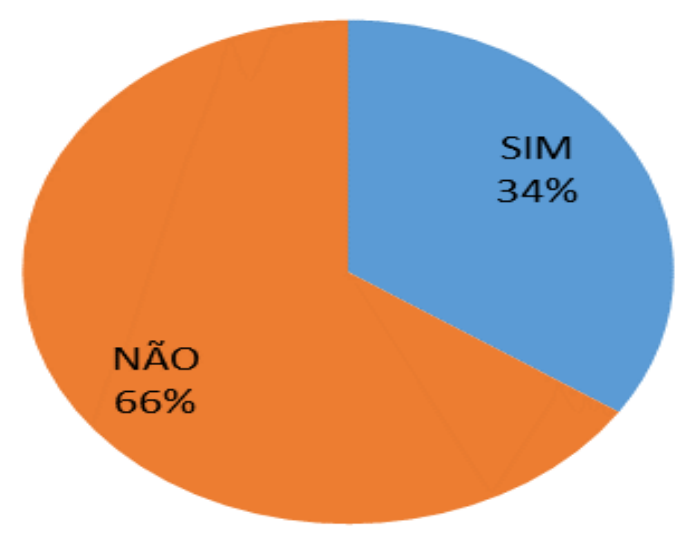

Fonte: Ribeiro RAB, et al., 2020.

Por fim, foi analisada a ocorrência de ter tido, em algum momento, Doenças Sexualmente Transmissíveis (DST) em mulheres com exames sugestivos de vaginose bacteriana na ESF escolhida para a pesquisa. No universo de 64 pacientes, apenas 2 mulheres relataram ter tido DST (3\%), enquanto a maioria, $97 \%$ relatam nunca ter tido (Gráfico 4 ).

Gráfico 4 - Avaliação de ocorrência de DST em mulheres com exames sugestivos de vaginose bacteriana.

\section{TEVE/TEM ALGUMA DST}

SIM

$3 \%$

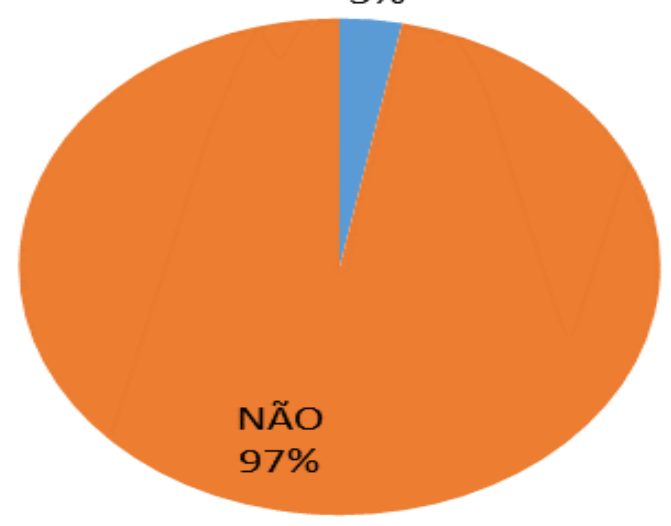

Fonte: Ribeiro RAB, et al., 2020.

\section{DISCUSSÃO}

O estudo contribui para o conhecimento acerca do perfil epidemiológico das 64 mulheres que realizaram PCCU com resultado de vaginose bacteriana no período de Janeiro de 2014 até Abril de 2016 realizados 
Belém - PA. O perfil epidemiológico dessa população pode fornecer base de dados estatísticos para que sejam utilizados em ações de promoção, prevenção e tratamento da vaginose bacteriana.

Devido ao preenchimento incorreto dos prontuários na Unidade de Saúde foi necessário adotar o uso de um questionário próprio, autoaplicável para análise das variáveis apontadas como fator de risco para vaginose bacteriana. $O$ uso do questionário também contribuiu para atualização de informações das pacientes nos prontuários.

Contudo, destaca-se que o preenchimento incorreto dificulta a procura e análise de dados pela Secretaria de Saúde sem a necessidade de encontrar as pacientes, dificultando a possibilidade de desenvolvimento de estratégias e políticas públicas direcionadas para a população, devendo então que haja a capacitação de preenchimento correto destas informações pela Secretaria de Saúde do local, fato encontrado em diversos estudos que sinalizam a dificuldade de desenvolver ou concluir qualquer estudo epidemiológico na área da atenção básica (estratégia saúde da família ou unidade básica de saúde) pelo preenchimento incompleto das informações por fatores tais como negligência ou agilidade para atender várias pacientes deixando de completar o prontuário que, parecem desnecessárias a primeiro momento, contudo fazem diferença para traçar um perfil epidemiológico das pacientes para desenvolvimento de estratégias e ações de educação em saúde ou de combate a alguma doença (MILHOMEMS PM et al., 2014).

$\mathrm{Na}$ análise dos resultados, a faixa etária mais acometida é de $21-30$ anos, correspondendo a $34,37 \%$ das mulheres estudadas. Resultado este condizente com os dados apresentados na literatura que afirmam que a Gardnerella vaginalis está presente com maior frequência nas primeiras 3 décadas de vida, correspondendo ao início da vida sexual haja vista ocorrer maiores perturbações na flora bacteriana vaginal devido ao início da atividade sexual (muitas vezes sem utilização de preservativo), modificações hormonais provocados pela puberdade e mudança no padrão de higiene vaginal feito pela paciente (AMARAL A, 2012). A variável estado civil não pode ser definida como fator de risco para vaginose bacteriana, pois os resultados demonstram que $50 \%$ são solteiras e as outras $50 \%$ apresentam algum tipo de relação conjugal, demonstrando assim risco equivalente. Sendo assim, como apresentado o aumento do nível de escolaridade faz com que a mulher adquira melhores hábitos de saúde e higiene, maior conhecimento sobre formas de cuidados e prevenção (MILHOMEMS PM et al., 2014).

Diferente do apresentado no Perfil Epidemiológico de Mulheres no Estado de São Paulo em que há relação entre vaginose bacteriana e maior número de parceiros, o estudo que realizamos $62,5 \%$ das mulheres apresentam de 0-1 parceiro e apenas 4,67\% possuem mais de 6 parceiros, sendo assim, não há correlação entre múltiplos parceiros e a presença de vaginose bacteriana nas mulheres que realizaram PCCU na USF estudada (BRASIL, 2006),

A prevalência da vaginose bacteriana aumenta consideravelmente em casos com clínica de DST, quando comparada a quadros ginecológicos gerais (GIORDANO M, 2015). No estudo que realizamos, 97\% das mulheres afirmaram não ter DST.

A etiopatogenia da doença (Vaginose Bacteriana) leva em consideração que a flora vaginal normal da mulher (composta por Lactobacilos de Doderlein principalmente) foi alterada por diversos fatores. A função desses lactobacilos é proteger a vagina contra agentes patológicos por meio da produção e secreção do H2O2 (Peróxido de hidrogênio), mantendo o pH vaginal ácido, e impedindo a proliferação de agentes causadores de doenças (BRASIL, 2006).

Qualquer alteração que leve a diminuição do lactobacilos e/ou alteração de produção ou secreção de H2O2 propicia a proliferação de bactérias anaeróbias que vão levar ao quadro de Vaginose Bacteriana. Dentre esses fatores, são incluídos sabonetes e uso excessivo de ducha de limpeza que podem alterar a flora vagina (SOUZA G, 2012).

Foi analisado o uso de preservativos pelas mulheres pesquisadas, e diferente do que é recomendado pelo Ministério da Saúde, a maior parte delas, $66 \%$ não faz uso nas relações sexuais, aumentando assim o risco de transmissão de vaginose bacteriana por contato íntimo ou relação sexual, como o risco de contrair 
DST (Doença Sexualmente Transmissível) e perturbação da flora bacteriana vaginal pelo contato com secreções do parceiro, propiciando o aparecimento da vaginose bacteriana (SOUZA G, 2012). O uso do DIU (Dispositivo Intra-Uterino) pode perturbar o equilíbrio normal de bactérias na vagina por questões hormonais liberados pelo próprio dispositivo (SOUZA G, 2012) e aumentar o risco de vaginose bacteriana, no entanto apenas $6 \%$ das mulheres do estudo possuem DIU.

A vaginose bacteriana constitui causa comum de queixa ambulatorial durante o pré-natal. Seu diagnóstico é feito a partir da queixa da gestante, e associa-se a vários efeitos adversos à saúde, incluindo o parto prematuro e a aquisição de doenças sexualmente transmissíveis, tornando-se um problema de saúde pública (SOUZA G, 2012). Através dos resultados é possível observar maior prevalência de vaginose entre mulheres que tiveram filhos $84,38 \%$ se comparadas às que não possuem $15,62 \%$.

A importância do diagnóstico precoce e da educação em saúde para diminuição de casos é fundamental. É comprovado que se não tratado ou diagnosticado de forma tardia, a vaginose bacteriana pode gerar consequências tais como risco de adquiri o vírus HIV (Vírus da Imunodeficiência Humana) e outros patógenos concomitantes a vaginose e, em mulheres gestantes, pode levar a parto prematuro, corioamnionite, endometrite, baixo peso do recém-nascido, infecção neonatal e ruptura prematura de membranas ovulares (SOUZA G, 2012).

Para esta pesquisa, o objetivo de encontrar o perfil epidemiológico das pacientes com vaginose bacteriana afim de desenvolver métodos e ações em saúde específicas para a população que possui esta patologia, permitindo com que haja a diminuição de tempo e aumento da efetividade das ações em saúde, além de diminuição de perda de investimento de verba para desenvolvimento de materiais ou composição de ações que não serão utilizados, diminuindo custos e melhorando o processo saúde doença da população do local (SOUSA G, 2012).

Um viés deste presente trabalho foi a associação do grupo familiar com a presença de vaginose bacteriana nas mulheres, essa associação não deve ser incluída como fator de risco, de modo que o grupo familiar não interfere na saúde intima da mulher. Um outro viés da pesquisa, se dá pelo fato de a população pesquisada ter uma alta taxa de vaginose bacteriana, isso faz com que a sensibilidade do questionário seja aumentada, contrapondo a especificidade que será diminuída nesta análise.

\section{CONCLUSÃO}

Com base nos dados apresentados, pode-se concluir que o perfil epidemiológico das pacientes com diagnóstico de vaginose bacteriana atendida na USF escolhida pela pesquisa, no período de janeiro de 2014 a abril de 2016 mostrou que mulheres jovens de baixa renda e com nível de escolaridade até o ensino médio apresentaram maior frequência de vaginose bacteriana. No entanto o grupo familiar e número de parceiros não influenciam, de acordo com estudos demográficos, na ocorrência de vaginose bacteriana. Incluindo nesse aspecto o uso de DIU e preservativos sexuais e ocorrência prévia de DST's. A compreensão do perfil epidemiológico das pacientes é de fundamental importância para a construção de estratégias direcionadas para esse grupo, desenvolvidas pela gestão, em conjunto com a população. Pretende-se, portanto, sensibilizar a gestão para o redimensionamento do atendimento nas unidades de saúde do município as mulheres em situação de risco a vaginose bacteriana, com especial atenção à realização do diagnóstico o mais precocemente possível e compreensão do panorama da doença na comunidade; assim como fomentar a discussão de estratégias para subsidiar as práticas de serviços de saúde, com vistas como controle e prevenção da doença e promoção da saúde da mulher e em sentido mais amplo, para toda a sociedade.

\section{REFERÊNCIAS}

1. AMARAL A. Incidência de Gardnerella vaginalis nas Amostras de Secreção Vaginal em Mulheres Atendidas pelo Laboratório Municipal de Fraiburgo. Revista de Ciências Farmacêuticas Básica e Aplicada; 2012. 
2. BRASIL. A importância do uso da camisinha nas relações sexuais, para evitar gravidez indesejada e riscos de contaminação por doenças sexualmente transmissíveis (DSTs). Departamento de Vigilância, Prevenção e Controle das IST, do HIV/Aids e das Hepatites Virais; 2006.

3. BRASIL. Ministério da Saúde, Instituto Nacional do Câncer, Biblioteca Virtual em Saúde, Exame preventivo do câncer de colo uterino (Papanicolau); 2011.

4. CAMARGO KC, et al. Secreção vaginal anormal: Sensibilidade, especificidade e concordância entre o diagnóstico clínico e citológico. Rev. Bras. Ginecol. Obstet.; 2015.

5. FERREIRA ECMF, et al. Vaginose Bacteriana Recorrente: Atualidades no manejo terapêutico. Rev. Pesq Saúde; 2013; 14(1): 55-58.

6. GIORDANO M. Dispositivo intrauterino de cobre. FEMINA; 2015 v. 43 Suppl. 1.

7. JALIL E. Abordagem Racional dos Corrimentos Vaginais. Febrasgo, 2006.

8. JALIL EM, et al. Abordagem Racional dos Corrimentos Vaginais. Universidade Federal da Bahia. Hospital Universitário Professor Edgard Santos - Serviço de Ginecologia; 2006.

9. LIMA AP. Ocorrência de Vaginose Bacteriana no Exame Citológico de Pacientes de um Hospital de Curitiba. Rev. Saúde e Desenvolvimento; 2015

10. MILHOMEMS PM, et al. Prevalência dos agentes etiológicos das vulvovaginites através de resultados de exames citopatológicos. Rev. Investig Bioméd. 2014; 6: 92-102.

11. NAI GA, et. al. Frequência de Gardnerella vaginalis em esfregaços vaginais de pacientes histerectomizadas. Rev. Assoc. Med. Bras; 2007; 53(2):162-165.

12. OLIVEIRA AB, et al. Prevalência de gardnerella e mobiluncus em exames de colpocitologia em Tome-Açu, Pará: Rev. Para. Med; 2007; 21(4):47-51.

13. TORTOLA GJ, et al. Microbiologia. 8a ed. Porto Alegre: Artmed, 2005.

14. SOARES G, et al. Correlação entre a presença de patógenos e alterações reativas benignas em esfregaços cervicovaginais. Gestão e Saúde, Brasília,DF. Brasil; 2016; v. 7, n. 2, p. Pág. 549-562.

15. SOUZA G. Tratamento das vulvovaginites na gravidez. Femina; 2012 v. 40 nำ. 